\title{
A Comparison of Early Field Results of White Pine Blister Rust Resistance in Sugar Pine and Western White Pine
}

Richard A. Sniezko, Andrew Bower, and Jude D anielson

Additional IndeX words. white pine blister rust, C ronartium ribicola, western white pine, Pinusmonticola, sugar pine, Pinuslambertiana, resistance, bark reaction

Summary. Seedlings from 12 sugar pine (Pinuslambertiana Dougl.) and 13 western white pine (Pinus monticola Dougl.) families were planted at H appy C amp, C alif., in 1996. A ssessment in Summer 1999 indicated moderate levels of white pine blister rust (C ronarti um ribicola Fischer) infection. This paper focused on the species differences and showed that sugar pine had a higher incidence of stem infection (active and inactive cankers) and more stem infections per tree than western white pine. An unexpected result was the very high percentage of infections that were bark reactions (completely inactivated infections), despite the fact that only some of the families of both species were selected for this mechanism. Assessments in subsequent years will track the future performance of the two species and of the individual families.

$\mathrm{n}$ the Pacific N orthwest Region, the U SD A Forest Service has been screening sugar pine (SP) and western white pine (WWP) parent trees from 0 regon and Washington for resistance to white pine blister rust (WPBR) since the late 1950s. Progeny of over 10,000 phenotypic selections from natural stands from a range of land ownerships have been evaluated for resistance at the D orena G enetic Resource $C$ enter (DGRC). Seedlings are examined for 5 years following inoculation for an array of resistance mechanisms (Sniezko, 1996). Less than $5 \%$ of the WWP and SP phenotypic selections tested with open-pollinated progeny have more than $30 \%$ canker-free progeny, and over $95 \%$ of seedlings develop needle lesions and most develop stem cankers, and subsequently die within the 5-year evaluation period. The main focus of the operational WPBR screening program at the DGRC has been to inoculate seedling progeny of phenotypically resistant selections from natural stands of WWP and SP, to select the best progeny in these screening trials for propagation in seed orchards, to produce rust resistant seed, and to breed the best selections to enhance resistance.

\footnotetext{
U SD A Forest Service, D orena G enetic Resource Center, Cottage Grove, O re.

The cooperation of U SD A Forest Service's Region 5 (Pacific Southwest Region) for use of their H appy Camp test site and the input given by $D$ ean $D$ avis and $D$ eems Burton to the planting and with the first assessment are gratefully acknowledged. I nput from B.B. Kinloch and Westfall from U SD A Forest Service's Pacific Southwest Research Station was al so valuable for this young trial. E stablishment of this planting was made possiblethrough funding from the U SD A Forest Service, Forest H ealth and Protection Program, with special assistance from the Pacific $\mathrm{N}$ orthwest Region. Thanks are also due to L ee Riley and other personnel at DGRC who organized the seedling culture and transport of plants. Robert D anchok, Sally L ong, and Ann Willyard provided vital help with the rust assessment in summer of 1999. The cost of publishing this paper was defrayed in part by the payment of pagecharges. U nder postal regulations, this paper therefore must be hereby marked advertisement solely to indicate this fact.
} 
Table 1. H eight and number of white pine blister rust stem infections (active and inactive) per tree by species at time of 1999 assessment of 1996 planting at $\mathrm{H}$ appy $\mathrm{C}$ amp, $\mathrm{C}$ alif.

\begin{tabular}{lcc}
\hline Parameter & Sugar pine & W estern white pine \\
\hline H eight [cm (inches) ] & $88.5(34.8)$ & $75.6(29.8)$ \\
N o. of infections per tree (all trees) & 1.63 & 0.56 \\
N o. of infections/ tree (infected trees only) & 2.42 & 1.69 \\
Range of no. infections/ tree & $0-17$ & $0-9$ \\
\hline
\end{tabular}

Little is known about how individuals selected for different resistance mechanisms in short-term screening perform in the field in the Pacific northwestern U .S., especially mechanisms such asbark reaction (H off, 1984) and tolerance (H off, 1986), which are exhibited after the fungus has entered the stem. At least one type of major gene resistance ( $M$ GR), a hypersensitive reaction in the needles that prevents stem infection, appears to be present in both SP and WWP, but MGR appears to occur at low frequency in natural stands (Kinloch et al., 1970, 1999). H owever, localized strains of WPBR render these mechanisms ineffective; the $\mathrm{H}$ appy $\mathrm{Camp}$ (HC) strain affecting SP (Kinloch and Comstock, 1981) and the Champion $M$ ine (CM) strain affecting WWP (Kinloch et al., 1999). N ot all families having a high incidence of canker-free seedlings have the identified major generesistance, but operational screening methodsused thusfar do not allow for clear separation of several possible mechanismsthat may yield canker-free seedlings.

Few well-replicated field plantings have been established to examine gainsfrom WPBR resistancescreening and the performance of resistant families, as well as the relative field resistance of SP and WWP. H off et al. (1980) examined the relative resistance of seedlings of 18 species of $\mathrm{N}$ orth American, European and Asian white pines (Pinus L.), and the frequency of six mechanisms of resis- tance, and Bingham et al. (1973) assessed percent infection and number of cankers per tree on 5-year-old WWP seedlings exposed to natural inoculum in the field for 2 years. They reported that percent infection, and number of cankers per tree in these field tests, closely matched results from artificial inoculation in nursery tests. Results presented here examine species differences in rust resistance using a 1996 planting of 12 SP and 13 WWP families at one planting site ( $\mathrm{H}$ appy $\mathrm{C}$ amp, Calif.). This site is noteworthy for the $\mathrm{H}$ appy Camp strain of WPBR. Detailed results are presented here only for early height growth, infection percent, and number of infections per tree and a brief overview of differences in stem infection types by species. To date, any differences between families have not been analyzed, and will not be discussed.

\section{Materials and methods}

The planting was established at $\mathrm{H}$ appy Camp in Spring 1996 with 10 container stock from a mixture of resistant and nonresistant families. Similar, but smaller plantings have been established at three sites in $0 \mathrm{r}$ egon, but infection levels to date are low, and formal assessments have not been done. Twelve SP and 13 WWP families were planted in 12 blocks in a randomized complete-block design. Four seed lings per family were planted per block, but for several families only two or three seedlings were available, or two trees from one container were planted at the samespot. 36 to 52 trees were planted per family, with most families having 48 or 49 seedlings. Seeds were sown for both species in late $M$ arch 1995 , but due to differences in early seedling growth, the SP seedlings were nearly twice as tall as the WWP. T rees were planted in fourtree row-plots, with each family represented only once in each block. For each species, families were selected for a range of resistance mechanismsusing results from previous screening at D GRC following artificial inoculation.

Assessment in 1999 included tree height, number of cankerson the bole, type and number of infections, damage, and vigor. Infection types were classified as normal $(\mathrm{N})=$ normal active stem infection, bark reaction (BR) = canker inactive or corked out, partial bark reaction $(P B R)=$ bark reaction with some area of canker still active, and blight $(B L)=$ inactive canker on a branch that was killed. Total number of infections per tree, both active and inactive, was obtained by summing $N$, $P B R, B R$, and $B L$. Trees with more than one infection could have two or more different types of infections, including both active and inactive infections.

An analysis of variance (AN OVA) was performed to assess species and block differences in the percentage of treesthat were infected, using thefamily block means for each species. An ANOVA was also used to examine differences in height and the number of infections per tree, using the SAS system (SAS Institute Inc., 1989). Because of the larger size of the SP seedlings, and the presence of the $\mathrm{HC}$ strain, SP was expected to have more infection than the WWP. To partially account for this difference in infection frequency, the analysis of the number of cankers per tree was repeated, first including all trees measured, then including only the infected trees. A chisquared test of independence ( $G$ omez

T able 2. O bserved and expected White pine blister rust stem infections by category (active and inactive types) and species in 1999 on the 1996 planting at $\mathbf{H}$ appy C amp, C alif.

\begin{tabular}{|c|c|c|c|c|c|}
\hline \multirow[b]{2}{*}{ Parameter } & \multicolumn{2}{|c|}{ Sugar pine } & \multicolumn{2}{|c|}{ Western white pine } & \multirow[b]{2}{*}{ O verall } \\
\hline & O bserved & Expected & O bserved & Expected & \\
\hline Normal infection & 256 (26.9\%) & 267 & $111(31.2 \%)$ & 100 & 367 \\
\hline Bark reaction & $394(41.3 \%)$ & 370 & $114(32.0 \%)$ & 138 & 508 \\
\hline Blight & $169(17.7 \%)$ & 168 & $62(17.4 \%)$ & 63 & 231 \\
\hline Total no. of infections & 953 & & 356 & & 1309 \\
\hline
\end{tabular}


T able 3. Percentage of trees with blister rust stem infections by category (active and inactive types) and species, using only on trees with stem infections based on 1999 assessment of $1996 \mathrm{H}$ appy C amp, C alif., planting. ${ }^{2}$

\begin{tabular}{|c|c|c|}
\hline Parameter & Sugar pine & Western white pine \\
\hline Normal infection only (\%) & 14.0 & 28.9 \\
\hline Partial bark reaction only (\%) & 9.2 & 14.7 \\
\hline Bark reaction only (\%) & 34.9 & 24.2 \\
\hline Blight only (\%) & 6.4 & 11.4 \\
\hline M ore than one type of infection (\%) & 35.5 & 20.8 \\
\hline N ormal infection ${ }^{+}$ & 33.3 & 40.3 \\
\hline Partial bark reaction ${ }^{+}$ & 25.4 & 27.0 \\
\hline Bark reaction ${ }^{+}$ & 60.3 & 35.5 \\
\hline Blight $^{+}$ & 25.4 & 20.9 \\
\hline
\end{tabular}

${ }^{2}$ For more than one type of infection, percentages include trees with only the one primary infection noted or trees with both the primary plus one or more other type of infection. D oesnot includethe uninfected trees, which is $29.2 \%$ for SP and $65.2 \%$ for WWP.

and Gomez, 1984) was used to analyze the stem infection data, to determine if there is an association between species and stem infection type.

\section{Results and discussion}

A total of 560 SP and 616 WWP were planted, of which $99.1 \%$ and $98.5 \%$ (555 and 607 ) respectively were still alive in lateJ une 1999. The difference in height between the two species at the time of planting was still evident in the mean height at the time of measurement, with SP $17 \%$ taller than the WWP (Table 1). T he percentage of trees infected was two times higher in SP, with $70.2 \%$ of the living trees infected, than in WWP with only $34.3 \%$ of the living trees infected. Of these infected trees, $27.5 \%$ of the SP had only 1 canker and $42.7 \%$ had more than one canker, while $21.8 \%$ of the WWP had 1 canker and only $12.5 \%$ had more than one canker. The results of the ANOVA indicate that both the difference in infection percent between species and blocks are both significant ( $P=0.0001$ and 0.0068 respectively). There were a total of 953 cankers on the 393 infected SP, and 356 cankers on the 211 infected WWP, with the mean and range of the number of infections per tree higher for SP, both including and excluding the noninfected trees (Table 1). A higher percentage of infection and number of cankers per tree in SP might be expected because of the larger size of the trees and presumably a larger target area, as well as the presence of the $\mathrm{H} \mathrm{C}$ strain of rust at this site (SP trees with MGR could become infected, while WWP trees with M GR could not be infected); however, the higher percentage may also be an indication of higher relative susceptibility of sugar pine.

Results of the second ANOVA indicate that when all trees are included in the analysis, there are significant differences between species for both height $(P \leq 0.0001)$ and number of cankers per tree ( $P \leq 0.0001)$. For both variables, there was also a significant (block $\times$ species) interaction $(P=$ $0.0085)$ and $(P=0.0047)$ respectively, but the block factor was significant only for height $(P=0.0058)$. When only the infected trees are included in the analysis, the difference between species was still highly significant for both height $(P=0.0005)$ and number of cankers $(P=0.0014)$. The (block $x$ species) interaction was also still significant for height $(P=0.0326)$, and the block factor was nearly significant $(P=0.0829)$. N either the block nor (block $\times$ species) interaction was significant for number of cankers.

While the greater level of infection on SP might be expected, the very high incidence of bark reaction on both the SP and the WWP was not. Incidence of bark reaction is generally very low in offspring of phenotypic selections in rust screening at D GRC, but a few open-pollinated families do exhibit greater than $25 \%$ incidence of bark reaction (unpublished data). $\mathrm{H}$ owever, $41.3 \%$ of the cankers on the $\mathrm{SP}$, and $32.0 \%$ of the cankers on the WWP were bark reactions, (T able 2 ). A chi-squared test for independence of the data in Table 2 indicates that for the total number of each canker type, ignoring families, an association does exist between species and canker type $\left(\chi^{2}=12.272, P=0.007\right)$. The observed number of normal and partial bark reaction cankers was lower than expected for SP, and higher than expected for WWP, while the opposite was observed for the bark reaction infections, with SP having higher and WWP having lower than expected observed numbers of bark reactions (Table 2). When including only the infected trees, $60.3 \%$ of the SP and $35.5 \%$ of the WWP trees had at least one bark reaction (and possibly 1 or more other canker types as well) (Fig. 2 , photo of tree with both a normal canker and abark reaction), and 34.9\% and $24.2 \%$ of the SP and WWP trees, respectively, had only bark reaction type cankers (Table 3).

The reason for the high incidence of bark reactions is unknown. $\mathrm{H}$ unt (1997) isolated several different types of fungi from bark reaction phenotypes in WWP, and reported that the most frequently isolated organism, phoma wilt (Phoma herbarum Westend.), when artificially inoculated onto both healthy and blister rust infected seedlings, produced lesionsidentical to bark reaction lesions. $\mathrm{H}$ e suggests that many bark reactions are a result of fungi other than $C$. ribicola. Resistance screening at DGRC (Sniezko, 1996), and the work of Kinloch and D avis (1996) and H off (1986) has shown bark reaction to be a real and durable resistance mechanism. H owever, it is possible that on these young trees at the $\mathrm{H}$ appy $\mathrm{Camp}$ site, there are other biological organisms or confounding environmental factors that are causing the high levels of bark reaction observed.

This first, early assessment indicates that sugar pine is more susceptible than western white pine to blister rust infection at thisfield site, and both species exhibit moderate levels of bark reaction at this early age. L ater assessments will provide information on differential rates of mortality following stem infection, as well as any longterm differences in bark reaction and tolerance between the species, and families within the species. Continued assessments of field plantings such as this one will provide essential validation of results of artificial inoculation tests, as well as some information on the current gains in rust resistance from seed orchards.

\section{Literature cited}

Bingham, R.T., Hoff, R.J., and G.I. $M C D$ onald. 1973. Breeding blister rust 
resistant western white pine. VI. First results from field testing of resistant planting stock. U SDA For. Serv. Res. N ote INT179.

Gomez, K.A. A.A. Gomez. 1984. Statistical procedures for agricultural research. Wiley, N ew York.

H off, R.J . 1984. R esistanceto C ronartium ribicola in Pinus monticola: $\mathrm{H}$ igher survival of infected trees. U SDA For. Serv. Res. N ote IN T-343.

H off, R.J. 1986. Inheritance of the bark reaction resistance mechanism in Pinus monti cola infected by Cronartium ribicola. U SD A For. Serv. Res. N ote IN T-361.

H off, R., R.T. Bingham, and G.I. $M$ cD onald. 1980. Relative blister rust resistance of white pines. Eur. J. For. Pathol. 10:307-316.

H unt, R.S. 1997. Relative value of slowcanker growth and bark reactions as resistance responses to white pine blister rust. Can. J. Plant Pathol. 19:352-357.

Kinloch, Jr., B.B., G.K. Parks, and C.W. Fowler. 1970. White pine blister rust: simply inherited resistance in sugar pine. Science 167:193-195

Kinloch, Jr., B.B. and M . Comstock. 1981.
Race of Cronartium ribicola virulent to major gene resistance in sugar pine, Plant $D$ is. R pt. 65:604-605.

Kinloch, B.B. and D. D avis. 1996. M echanisms and inheritance of resistance to blister rust in sugar pine, p. 125-132. In: B.B. Kinloch, M . M arosy, and M .E. H uddleston (eds.). Sugar pine: Status, values, and roles in ecosystems: Proceedings of a symposium presented by the California Sugar Pine $\mathrm{M}$ anagement $\mathrm{C}$ ommittee. U niv. $\mathrm{Ca}$ lif. D iv. Agr. N atural R esourcesPubl. 3362.

Kinloch, Jr., B.B., R.A. Sniezko, G.D. Barnes, and T.E. Greathouse. 1999. A major gene for resistance to white pine blister rust in western white pine from the Western Cascade Range. Phytopathology 89:861-867.

SASI nstitutel nc. 1989. SAS/ ST AT user's guide. version 6. 4th ed. vol. 2. SAS Institute Inc., Cary, N.C.

Sniezko, R.S. 1996. D eveloping resistance to white pine blister rust in sugar pine in O regon, p. 125-132. In: B.B. Kinloch, M. $M$ arosy, and M .E. H uddleston (eds.) . Sugar pine: Status, values, and roles in ecosystems: Proceedings of a symposium presented by the California Sugar Pine $M$ anagment Committee. U niv. Calif. Div. Agr. N atural Resources Publ. 3362. 